\title{
El Hijo santo, novela de Gabriel Miró. Consideraciones sobre un olvido
}

\author{
Miguel Ángel Lozano Marco \\ Universidad de Alicante
}

El año de 1909 es de singular importancia en la vida de Gabriel Miró. Después del premio conseguido el año anterior con Nómada, en el concurso convocado por El Cuento Semanal, su firma fue apareciendo con cierta asiduidad en destacadas páginas de la prensa madrileña, en Los Lunes de El imparcial y en Heraldo de Madrid, además de contribuir con un par de artículos a la revista Prometeo. El número de sus colaboraciones aumenta notablemente, pero, ante todo, el estímulo del éxito literario dio como resultado que su obra novelística se incrementara con algunos títulos. Por lo pronto todo parece indicar, si nos acercamos a su biografía, que el reconocimiento público que supone un premio nacional, así como públicas recomendaciones de hombres notables ${ }^{1}$, deparó al escritor alicantino ciertos destinos burocráticos que,

1 El Diario de Alicante recoge en 1908 cartas de Salvador Rueda (29 de abril), del ingeniero Nicasio Mira (5 de mayo) y de Óscar Esplá ( 7 de mayo) denunciando el hecho de que un escritor de tan altas cualidades tuviera que malograrse en el «diario despacho de expedientes que tantas energías consume» (carta de $\mathrm{N}$. Mira), como oficial en la dirección del Hospital Provincial, donde trabajaba desde mayo de 1906, en lugar de dedicar su tiempo a la creación literaria. Rueda y Esplá solicitan que la ciudad de Alicante, mediante su Diputación o Ayuntamiento, conceda a su escri- 
aunque no fueron duraderos ni bien remunerados ${ }^{2}$, le permitieron disponer de algún tiempo para dedicarse a la creación literaria. De este modo pudo acabar la redacción de Las cerezas del cementerio, novela concebida «antes que Del vivir» ${ }^{3}$, en la que el escritor puso su ambición juvenil. En el epistolario que conocemos se alude a la necesidad de tiempo y sosiego para poder dar fin a la obra ${ }^{4}$. Paralelamente a la escritura de esta obra de mayor empeño van saliendo a la luz algunas novelas cortas que ha ido también concibiendo en los últimos dos años, por lo menos. 1909 es el año de Los Contemporáneos, y en esta colección de relatos, fundada por Zamacois a imagen y semejanza de El Cuento Semanal, vieron la luz ese mismo año La palma rota, El hijo santo y Amores de Antón Hernando ${ }^{5}$, y, ya en 1912, La señora, los suyos y los ótros. Gabriel Miró perseveró en el género que le había deparado un notorio éxito tal vez porque la índole del relato que contienen y potencian dichas publicaciones se avienen perfectamente con el tipo de novela que estaba realizando: una novela que abandona el argumento complicado y municiosamente desarrollado, siguiendo una secuencialidad temporal continuada y precisa, para convertirse en una narración de carácter presentativo que somete la trama argumental a un tratamiento elíptico,

tor una pensión de cincuenta duros mensuales. Nicasio Mira solicita de la Diputación que Miró fuera nombrado cronista provincial en sustitución del destino que venía desempeñando. Para los datos biográficos es imprescindible acudir al documentado libro de Vicente Ramos, Gabriel Miró, Alicante, Instituto de Estudios Alicantinos, 1979.

2 Fue nombrado cronista provincial en agosto de 1909, después de haber sido relevado de su puesto de oficial en la dirección del Hospital Provincial para pasar a la Secretaría de la Diputación, pero quedó cesante en febrero de 1910. En marzo de ese año es nombrado auxiliar del Delegado del Gobierno en la Junta de Obras del Puerto, hasta que en diciembre Federico Soto, al tomar posesión de la alcaldía de la ciudad, lo llama a su lado como su secretario particular. Es repuesto como cronista en octubre de 1911. A comienzos de 1914 traslada su domicilio familiar a Barcelona.

3 Así lo afirma en la carta a sus amigos Enrique Puigcerver y Ernesto Chápuli, fechada el 22 de noviembre de 1909, que reproduce Vicente Ramos, op. cit., págs. 145-147.

4 En la carta aparecida en el Diario de Alicante ( 25 de enero de 1908), en que agradece el ofrecimiento del director de El Demócrata para publicarle Las cerezas del cementerio, Miró confiesa: «Yo no soy un profesional del arte. Escribo cuando puedo. Mi libro, Las cerezas del cementerio, cuya traza compuse hace cuatro años, no está escrito. Necesito tres o cuatro meses de sosiego». En la carta citada en la nota anterior insiste sobre este sunto, y dice tener redactado la mitad del libro.

5 Las novelas fueron publicadas, sucesivamente, el 29 de enero, 11 de junio y 26 de noviembre de 1909. 
potenciando cada uno de los momentos escogidos mediante la intensificación poética del lenguaje y la intensificación patética de los sucesos $^{6}$.

Las novelitas que aparecen publicadas en ese año fueron luego hallando acomodo en distintos volúmenes, para terminar ocupando un lugar en las Obras completas, a excepción de El hijo santo, fatalmente condenada a la efímera vida de una revista semanal productora de cientos de relatos que pasaron, en su mayor parte, a quedar amontonados en la fosa común del olvido, o en la trastienda de una librería de viejo. Su mismo autor parece no recordarla y, sin haberla explícitamente repudiado, la marginación a que fue sometida no le permitió alcanzar esa cierta perdurabilidad que proporciona la publicación en forma de libro. Fue Miró, como sabemos, un escritor exigente, y esa exigencia le llevó a repudiar los dos primeros libros, o «ensayos de novela», por él publicados en los primeros años del siglo, La mujer de Ojeda e Hilván de escenas, obras que preceden al hallazgo de su propia y personal estética; del mismo modo,parte de los cuentos reunidos en los volúmenes titulados Del huerto provinciano y Los amigos, los amantes y la muerte fueron desechados cuando selecciona en su madurez las piezas que consideró más apropiadas, agrupándolas en Corpus y otros cuentos ${ }^{7}$. El hijo santo es, pues, la única novela corta, de entre las que aparecen en las colecciones o revistas, que quedó en el olvido. No es fácil conocer las razones de dicho olvido; pudo ser simple inadvertencia, o tal vez no la consideró de la misma calidad que el resto de sus relatos. Sin embargo ahora, al examinar esta parcela de la creación mironiana, no sólo evidenciamos su calidad, sino que incluso podemos preferirla a otras que, como La palma rota, han sido varias veces reeditadas. Lo que a continuación quiero apuntar no va tan sólo encaminado a tratar de comprender y explicar las razones de un olvido, sino más bien pretendo es-

6 Un ejemplar estudio de los procedimientos narrativos mironianos, realizado sobre su novela más lograda, puede encontrarse en el libro de Yvette E. Miller, La novelística de Gabriel Miró, Madrid, Ediciones y Distribuciones Códice, S. A., 1975. Recientemente el profesor José Carlos Mainer ha realizado una aportación fundamental sobre el género novela corta y su específica configuración en el molde editorial en que iba a difundirse: «EI Cuento Semanal (1907-19.12): Texto y contexto», en Formas breves del relato, Estudios coordinados por Yves-René Fonquerne y Aurora Egido, Universidad de Zaragoza, 1986, págs. 207-220.

7 De los veintinueve cuentos recopilados en aquellos dos tomitos - de 1912 y 1915 , respectivamente, pasan a Corpus y otros cuentos, en 1927, sólo trece. 
bozar unas consideraciones que, partiendo de conjeturas de ese olvido, puedan dar cuenta de algunos aspectos de la producción literaria de Gabriel Miró.

Como acabo de señalar, los relatos publicados en las colecciones de novelas cortas tienen, por el propio vehículo en que aparecen impresos, una vida efímera, de la que se pueden redimir, en cierto sentido, si posteriormente les cabe la suerte de salir de nuevo en las páginas de un libro. Esto reza, por supuesto, para aquellos escritores que no han quedado formando entre esa legión de «raros y olvidados» - o «promocionistas de El Cuento Semanal»- hacia los que sólo algún que otro historiador de nuestra literatura contemporánea lanza, de vez en cuando, una cariñosa mirada, «exhumando» sus obras de entre el polvo de algún anaquel. En el caso de El hijo santo ese acceso a la categoría de libro pudo haberse producido en fechas cercanas a su aparición, pues como sabemos gracias a una carte de Miró dirigida a sus amigos Enrique Puigcerver y Ernesto Chápuli, que se encontraban en América del Sur, el escritor tenía la intención de componer un volumen que contendría La palma rota, El hijo santo, Amores de Antón Hernando y Pasión; de esta desconocida novela nos dice que «aparecerá en un número de El Cuento Semanal de febrero ${ }^{8}$. Por lo cercano de la fecha de publicación podemos suponer que Pasión se encontraría en avanzado estado. Nada sabemos sobre ella, pero tal vez por lo que el título indica y por la fecha de composición aventuro que pudiera tratarse de una primera versión de Dentro del cercado, novela que, aunque fue publicada seis años después, aparece citada por su autor, con el título definitivo, en una carta fechada en septiembre de 1910, en la que habla de su pronta aparición ${ }^{9}$. El volumen que iba a recopilar las cuatro novelitas no se logró, y El hijo santo no halló acomodo en otro.

Pudo ser ésta una de las razones de su olvido, y lo aquí señalado tiene que ver con la manera en que se va configurando, editorialmente, parte de la obra de Gabriel Miró. No está de más recordar que esos tomos que reunían tres o cuatro novelas cortas no eran un buen negocio.

Carta citada en n. ${ }^{\circ} 3$.

9 «Pronto saldrá otra versión mía (de Lavedán); una novela: Dentro del cercado; un tomito de Crónica del licenciado Sigüenza [...]»; carta a Puigcerver citada por Vicente Ramos, Vida y obra de Gabriel Miró, Madrid, El Grifón de Plata, 1955, pág. 153. 
Julio Casares expresó su opinión sobre este asunto de manera clarificadora ${ }^{10}$. En primer lugar, el fracaso se produce porque los libros como el que pensaba componer Miró en 1909 no son sino «conglomerados circunstanciales de narraciones cortas, que no forman verdaderas colecciones» ${ }^{11}$; no están los relatos sometidos a un designio o a una peculiar disposición que fuera por sí interesante u original. En segundo lugar, Casares expone un criterio económico que podemos utilizar quí un tanto libremente adaptándolo al caso: si el lector interesado en las novelas cortas puede conseguir por cuarenta céntimos cuatro relatos de reconocidas firmas y de similares características a los que se recogen en ese volumen, difícil será que desembolse alegremente las tres cincuenta o cuatro pesetas que le cuesta el tomo. De ahí que las novelas cortas de Miró aparecieran siempre como complemento de otras novelas más extensas, pero no tanto como para, por sí solas, ocupar las trecientas páginas que viene a tener el volumen. Nómada acabó por acompañar a La novela de mi amigo, que fue escrita para ser publicada en forma de libro, tal vez porque ambas compartían un mismo tema, fruto de las preocupaciones de su autor en ese año de 1907 en que fueron redactadas. Las definiría, según expresé hace algunos años, «el drama de sus protagonistas: esa vitalidad desmesurada que es fatalmente ahogada por el medio; la inexorable frustración de unas vidas ansiosas de plenitud $\gg{ }^{12}$.

Más fácil es comprobar la relación temática que vincula Dentro del cercado, de mayor extensión y destinada al libro, con La palma rota, que le sirve de complemento para alcanzar el volumen de trescientas páginas que deseaba el editor Doménech - $\mathrm{e}$ incluso con la parte del relato aludido por el título de Los pies y los zapatos de Enriqueta en la ampliación del libro en 1927. A las dos primeras las calificó su autor de «novelas románticas», uniendo bajo un mismo calificativo obras de distinta categoría estética, aunque de cierta semejanza en el tema, que gira en torno a la imposibilidad de unas muchachas - las protagonistas-

10 En el capítulo «Cuentos y novelas cortas» de su libro Crítica efímera, Madrid, EspañaCalpe, 1962, págs. 202-233.

11 Ibíd, pág. 229.

12 Miguel Ángel Lozano Marco, «En torno a Los pies y los zapatos de Enriqueta, novela corta de Gabriel Miró», en el libro, Homenaje a Gabriel Miró. Estudios de crítica literaria, Alicante, Publicaciones de la Caja de Ahorros Provincial, 1970, pág. 107. 
para gozar del amor; casos de vidas frustradas o desperdiciadas ${ }^{13}$. De este modo El hijo santo no encontró libro en que pudiera ocupar un sitio, y permaneció en el lugar de su primera salida, una revista que sería cada vez de más difícil acceso para el curioso lector.

En el mismo tema de la novela podemos encontrar un nuevo motivo de marginación,por su relación con ciertas preocupaciones temáticas que hallaron brillante expresión en la narrativa realista decimonónica. La figura del sacerdote enamorado fue abordada repetidas veces desde distintas perspectivas en la novelística realista y naturalista, tan bien conocida por Miró, y en esta novelita podemos apreciar ciertas vinculaciones con dos obras representativas de esa temática, en las que el alicantino pudo hallar inspiración; me refiera a La Regenta y a Pepita Jiménez.

Los más conspicuos estudiosos de Miró, y quiero aludir a Edmund L. King y a Francisco Márquez Villanueva, han demostrado cómo en algunas ocasiones el novelista levantino utilizó motivos, argumentos, procedimientos, etc., de Valera o de Zola para componer ciertas obras; en los mejores casos, como en Las cerezas del cementerio o El abuelo del rey ${ }^{14}$, para crear con aquellos materiales recogidos obras de impresionante belleza y originalidad. El mismo novelista, en un escrito primerizo, muy iluminador sobre este aspecto, sacaba como conclusión de

13 Tema habitual en Miró. Yvette E. Miller señalaba como tema subyacente de Nuestro Padre San Daniel y El obispo leproso «la frustración desesperanzada de los personajes como resultado de sus vidas desperdiciadas» (op. cit., pág. 52). También Eugenio G. de Nora apunta la relevancia de este tema, esencial en su narrativa: «la injusticia brutal y absurda con que la felicidad escapa, de un modo $u$ otro, fatalmente, a los seres mejor dispuestos y dotados para ella, a los más dignos de recibirla», La novela española contemporánea (1898-1927), I, Madrid, Gredos, 1973, pág. 459.

14 Francisco Márquez Villanueva ha estudiado la utilización especial que Miró hace de ciertas novelas de Zola, del ciclo de los Rougon-Macquart, para construir, con materiales procedentes de ellas, relatos bien diferentes; en concreto son La fortune des Rougon para Las cerezas del cementerio (vide. su art. "Sobre fuentes y estructura de Las cerezas del cementerio" Homenaje a Casalduero, Madrid, Gredos, 1972, págs. 371-377) y La joie de vivre para El abuelo del rey, («Sobre fuentes y estructuras de El abuelo del rey», Nueva Revista de Filología Hispánica, s. XXIV, n. ${ }^{\circ} 2$ (1975), págs. 469-480). El prof. Edmund L. King ya nos había mostrado la influencia de don Juan Valera en el Miró más juvenil de su art. "Gabriel Miró y 'el mundo según es'», en Papeles de Son Armadans, LXII (mayo de 1961), págs. 121-142, y con más extensión en su Introducción biográfica a Gabriel Miró, Sigüenza y el Mirador Azul y Prosas de «El Ibero», Madrid, Ediciones de la Torre, 1982. 
la desdichada carrera de Aurelio Jiménez, aspirante a escritor que no había logrado hallar su originalidad, lo que de manera precisa declara en este párrafo de obligada cita:

La originalidad se tiene, no se busca.

Lo mejor y preferible es levantar grandiosos edificios sobre cimientos nuevos; pero también sobre los viejos pueden alzarse esbeltas construcciones radiantes de belleza que se distingan de las otras. Y cuando todo se encuentre cimentado o la inteligencia carezca de vista de Linceo y no descubra un solar virgen, construya, edifique por su cuenta, sobre lo que hubiere, tomando asuntos viejos (no ruinosos y desprovistos de interés) desde puntos de vista no gastados ${ }^{15}$.

En El hijo santo pudo Miró «edificar por su cuenta» tomando asuntos -o ideas, estímulos, etc. - de las obras citadas, pero modificándolos sustancialmente al incorporarlos a su propia creación. Quiero en este momento recoger la sugestiva indicación que la profesora Biruté Ciplijauskaité nos brindara en un estimulante trabajo ${ }^{16}$ en el que relaciona La Regenta con Nuestro Padre San Daniel y El obispo leproso a través de la oposición que advierte entre los sacerdotes protagonistas don Fermín y don Magín-, lo que le permite sintetizar una preciosa visión e interpretación, de la obra mironiana. En el sentido que antes apuntábamos, la autora del trabajo escribe: «Las coincidencias de detalle en la presentación de las figuras principales son numerosas y se dan casi siempre por inversión, casi como si Miró tuviera en cuenta a don Fermín al modelar su Magín» ${ }^{17}$. Alejándose, pues, de sus estímulos literarios, pero utilizando las incitaciones que ha recibido en la lectura y que ha ido modificando en su memoria al ir configurando su propia obra, Gabriel Miró ha creado relatos de fuerte originalidad en los que podemos encontrar, convenientemente transformadas, resonancias de obras literarias que despertaron su interés.

En el estudio que precede a mi edición de las Novelas cortas de Miró ${ }^{18}$ apunto que el nombre de Castroviejo, ciudad en que se desarro-

15 «Del natural», artículo publicado en EI Ibero por entregas, desde el 16 de marzo hasta el 16 de mayo de 1902, recogido por E. L. King en el libro cit. en nota anterior, pág. 144 .

16 «Don Fermín, ¿anti-modelo de don Magín?», en Actas del VII Congreso de la Asociación Internacional de Hispanistas (Venecia, 1980), publicadas por Giuseppe Bellini, Roma, Bulzoni, 1982, vol. I, págs. 307-315.

17 Ibid., pág. 308.

18 Alicante, Instituto de Estudios Juan Gil-Albert y Caja de Ahorros de Alicante y Murcia, 1986. Contiene El hijo santo. 
lla la mayor parte de la acción de El hijo santo, y que está construida tomando como modelo el Alicante de principios de siglo, es extraño y ajeno a la toponimia levantina, y parece remitir por su significado a Vetusta, por la vetustez del lugar, por la presencia del clero en la colegiata y sus alrededores, incluyendo ese Círculo Católico - especie de Casino clerical - tan bien dibujado, y por la misma figura del sacerdote asaltado por el amor, que vive su proceso sentimental en silenciosa expectación de sí mismo. Como en la novela de Clarín, el protagonista es sacerdote por imposición materna; ambas madres, doña Paula y doña Leocadia, son autoritarias, dominadoras, y vigilan celosamente la conducta de sus hijos; ambas son viudas. Pero mientras doña Paula ha hecho sacerdote a don Fermín movida por la ambición de riquezas que pueden conseguirse por medio de la iglesia y el poder que una jerarquía en ella confiere, doña Leocadia, tras la dolorosa experiencia de la muerte de su hijo menor y su marido, ambiciona la santidad para Ignacio. También las dos adivinan el proceso erótico de sus hijos, comportándose de manera opuesta: la señora vetustense censura con dureza, por el peligro que entraña para sus ambiciones, el trato de su hijo con Ana Ozores, pero comprende y hasta propicia los posibles escarceos sexuales que no han de trascender, mientras que la castrovejense proporciona a su hijo, cuando llega la primavera, el adecuado cilicio para preservar la castidad.

Dominados por sus respectivas madres, ambos sacerdotes presentan un carácter opuesto. Fermín de Pas, canónigo magistral de la catedral de Vetusta, figura relevante en la jerarquía eclesiástica de su diócesis, se caracteriza por su vitalidad ascendente, por su voluntad de poder, y por su robustez y fortaleza corporal; gusta de trocar la sotana por el traje de cazador, que resalta su varonil porte. Ignacio, beneficiado de la colegiata de Castroviejo, es un ser sometido, débil de carácter e ingenuo, que se avergüenza ante doña María por su apariencia de clérigo lugareño, vulgar y desmañado; vida humilde, de limitados horizontes, no puede sacar el partido que él desearía a su cualidad sobresaliente: su prodigiosa voz, asombro de los fieles cada vez que canta desde el coro de la colegiata ${ }^{19}$.

19 No está de más señalar también la importancia que tiene la descripción del ambiente del Círculo Católico, tan irónicamente retratado, que revela una parte del pulso vital de Castroviejo, cumpliendo un papel caracterizador similar, aunque en menor escala, al que cumple en Vetusta su inolvidable Casino. 
Como sabemos, Pepita Jiménez fue ya fuente inspiradora para el primer «ensayo de novela» mironiano ${ }^{20}$, y parece advertirse al fondo de la que nos ocupa. El ejemplar de la biblioteca de Miró, que ostenta bajo la fotografía de Valera el expresivo «iBendito seas!» escrito con pulso entusiasta por el joven alicantino ${ }^{21}$, carece de anotaciones o marcas en el texto y márgenes de la novela, pero muestra en cambio otra sencilla señal, fácil de encontrar en otros libros de su biblioteca particular, consistente en una doblez en el ángulo superior de la página; con ello va señalando momentos singulares del proceso de Luis de Vargas y pasajes que le interesan. Así, en la página 59 el aprendiz de escritor se fijaría en el momento en que el joven seminarista se acompleja ante Pepita viéndose «desmañado, torpe, corto de ingenio», con trazas de «estudiante humilde»; mozo lugareño incapaz de «inspirar pasiones», lo que revela el carácter mundano de Luis (del mismo modo que Ignacio siente parecidas tribulaciones ante la viuda). Ambos protagonistas viven la intensificación de su proceso amoroso en primavera, de abril a junio, y recurren de igual modo al Cantar de los Cantares, utilizando versículos del poema bíblico para aplicarlos a la mujer que aman, de manera directa y no simbólica.

Enamorados los dos de una joven viuda, Luis de Vargas es todavía seminarista, lo que permite el final feliz ya que puede abandonar su vocación al ser consecuente con sus sentimientos. El padre del muchacho, viudo como la madre de Ignacio, actúa de manera opuesta a como ésta lo hará, en lo que hallamos otro caso de inversión: procura, secretamente, los medios para que la feliz unión se produzca; y si al final declara que «tener un hijo santo hubiera lisonjeado mi vanidad», afirma también que la novia es «digna de trocarse por el cilicio y las disciplinas». Si la madre de Ignacio vive unida a un recuerdo doloroso que llena y orienta su vida $-\mathrm{y}$ la de su hijo-, el padre de Luis se ve remozado con el amor de los jóvenes. El ex-seminarista -o sacerdote frustradologra encontrarse a sí mismo en el amor, mientras que Ignacio acepta

20 Vide los fundamentales estudios de Edmund L. King citados en n. 14. Asimismo, el art. de Enrique Rubio Cremades, «Primeros ensayos novelísticos de Gabriel Miró: La mujer de Ojeda e Hilván de escenas», en VV.AA., Homenaje a Gabriel Miró, cit., págs. 75-100.

21 El ejemplar que leyó Miró es Pepita Jiménez, Madrid, Librería de Fernando Fe, $1890,12 .^{2}$ edición. También en su primera hoja, y escrito con la misma letra arrebatada que hay al pie del retrato, escribió el joven aprendiz de novelista debajo de su firma: «Libro adquirido de cuarta, quinta o centésima mano, ino sé!». 
con sumisión el desmoranamiento de todo en su vida, imposibilitado para seguir los caminos de salvación que advierte en el puro goce de lo que la vida le ofrece ${ }^{22}$.

Un tercer motivo que explique la marginación de El hijo santo puede encontrarse en la notable carga sentimental de un pasaje central de la novela, donde se roza peligrosamente con lo sensiblero sin llegar a caer en ello. Miró, como sabemos, es partidario de «decir las cosas por insinuación», y si este designio «se afirma más» en El obispo leproso, también se aprecia en el resto de su obra. El proceso amoroso del sacerdote está hábilmente narrado de esta manera insinuada; pero el suceso que determina su sacerdocio, la muerte de su hermano menor, Carlitos, cuando tenía cinco años, en un accidente doméstico, está contado con detalle por su madre, potenciando lo conmovedor del caso; y la narración de la muerte de un niño hecha por la propia madre corre el peligro, en literatura, de convertirse en una anécdota de fácil sentimentalismo. Como sabemos, en 1907 apareció en Revista Latina - que dirigía Francisco Villaespesa-, bajo el título de «Historia que no se cuenta», un breve relato que viene a coincidir, salvo pequeñas variantes o correcciones, con parte de los capítulos segundo y tercero de El hijo santo, más un capitulillo de enlace entre ambos fragmentos, escrito expresamente para esta ocasión, en el que nos encontramos con un personaje, inexistente en la novela de 1909, que sustituye a doña María como destinataria oyente del relato de la madre. ${ }^{23}$. Pues bien, el centro de interés de ese cuento publicado en una revista modernista lo constituye el mismo relato de la muerte de Carlitos. Resulta evidente que aquello que Miró destaca, publicándolo, en 1907, es lo que más le perjudicaría en la época en que va ordenando volúmenes de cara a las Obras completas de Biblioteca Nueva, en los años veinte, y lo que él escrupulosamente rechazaría; porque si algo se ataca con saña en aquellos años, es precisamente el sentimentalismo. No son tiempos para relatos emotivos aque-

22 El drama fundamental de Ignacio consiste en atisbar una vida más plena propiciada por el amor y el goce de los sentidos, y no poder acceder a ella. Es también una vida desperdiciada en la que todo se malogra, como se expresa en esta cita que da cuenta de sentimientos experimentados una tarde de mayo: «iQué ansias deliciosas siente el presbítero! Ansias que luego se deshacen dolorosamente en su misma concepción, sin haber tenido vida en la Vida» (ed. cit. en n. ${ }^{\circ} 18$, pág. 256).

23 Transcribo el texto de «Historia que no se cuenta» en el Apéndice de mi ed. de Novelas cortas, cit. 
llos en los que las élites literarias buscaban un arte «deshumanizado». Sin participar en esta orientación, porque en la obra de Miró siempre está presente el motivo, logrado de una manera implícita, compleja e inteligente, el escritor alicantino fue altamente estimado por poetas y prosistas de vanguardia, que reconocían en él un ejemplo y un magisterio ${ }^{24}$.

Pero las referencias a La Regenta o a Pepita Jiménez no explican la singularidad de El hijo santo. Miró leyó y aprendió en los realistas y naturalistas, y tomó el relevo generacional haciendo avanzar el género novela desde el punto en que aquéllos lo había dejado ${ }^{25}$. Creador solitario y no perteneciente a grupo, cenáculo, escuela, movimiento o tendencia, es, ante todo, el autor más representativo - y de más categoría y potencia estética- del tipo de novela que surge de la crisis del naturalismo y que va a parar a las fórmulas narrativas que llamamos de vanguardia. Miró es un hombre de su tiempo, por ello en El hijo santo, junto con un cierto realismo - no exento de ironía - en la descripción de la vida ciudadana, y un procedimiento naturalista en la visión de las mezquindades del mundo rural, encontramos el preciosismo, tan de épo$\mathrm{ca}$, en los ambientes que rodean a la hermosa viuda, y alusiones a las ideas filosóficas y estéticas representativas de la época modernista. Por el fondo de esta novela advertimos la presencia de Schopenhauer - ya citado en otras ocasiones por Miró, desde La mujer de Ojeda- en la ubicuidad del dolor y en el sentido de ver la vida como la historia de un sufrimiento. A Nietzsche lo encontramos en el tema de la vitalidad descendente del protagonista, en el desdén e indiferencia de los sanos, fuertes y ricos hacia los enfermos, débiles y humildes, y, sobre todo, en la idea que queda expuesta en aquella alusión, al final de La señora, los suyos y los otros, que bien pudiera situarse al frente de esta novela: « ¿No se queja Nietzsche del poco destino que hay en nuestra mira-

24 De Jorge Guillén es uno de los mejores ensayos sobre el arte de Miró y excelentes son las páginas que le dedicaron Pedro Salinas y Dámaso Alonso; vide también el art. de Francisco Jovier Díez de Revenga, «Gabriel Miró y los poetas del 27», en el Homenaje a Gabriel Miró, cit., págs. 243-263. De esencial importancia en este aspecto son los artículos que los escritores de la generación vanguardista publicaron en las páginas literarias de Heraldo de Madrid de 18 y 25 de enero de 1927, elogiando el arte de Miró y protestando por la desacertada crítica de Ortega a El obispo leproso.

25 Vide las iluminadoras consideraciones de Edmund L. King en su «Introducción biográfica) a Sigüenza y el Mirador Azul, cit.; esp. pág. 77. 
da?» ${ }^{26}$, aplicable al limitado horizonte del protagonista, y de Castroviejo. A esto hay que añadir el simbolismo de Maeterlinck, expresamente citado, de quien se toma esa visión de los niños marcados por la muerte, tal como aparece en el capítulo titulado «Los prevenidos» de su libro El tesoro de los humildes ${ }^{27}$.

Realismo, naturalismo, simbolismo, más Schopenhauer, Nietzsche y Maeterlinck, bien asimilados y adaptados a sus propias preocupaciones, sin olvidar una evidente ironía que ya va apareciendo en la narrativa mironiana, pueden definir, en parte, la situación literaria de esta olvidada - pero no desdeñable - novela, pieza que nos dice no poco sobre el proceso de aprendizaje del joven escritor y sobre sus sólidos fundamentos.

26 Los Contemporáneos, 30 de agosto de 1912. La cita procede de Así hablaba Zaratustra: «¿Por qué hay tanta renuncia, tanta abdicación en vuestros corazones?, ¿tan poco destino en vuestra mirada?»; la pregunta está hecha a la exacta medida de Ignacio, puede definir perfectamente al personaje. Sobre esta frase de Nietzsche vide F. Márquez Villanueva, «Sobre fuentes y estructura de Las cerezas del cementerio, pág. 377.

27 En la biblioteca particular de Miró se encuentra el ejemplar: Mauricio Maeterlinck, El tesoro de los humildes, traducción de Eusebio Heras, Valencia, F. Sempere y C. ${ }^{\mathrm{a}}$, Editores, (s.a.); no contiene anotaciones ni señales. 